$\underline{\xi}=$

\title{
Obstetric admissions to the critical care unit: a one year experience at a tertiary care referral centre of the developing country
}

\author{
Kriti Agarwal $^{1 *}$, Partha Mukhopadhyay ${ }^{2}$, Krishna Dahiya $^{3}$, Reetu Hooda $^{4}$, Sahil Sanghi $^{5}$, Kamal Narsaria $^{6}$, Gazal Garg $^{7}$ \\ ${ }^{1}$ Senior Resident, Department of Obstetrics \& Gynaecology, PGIMS, Rohtak \\ ${ }^{2}$ Professor, Department of Obstetrics \& Gynaecology, Medical College, Kolkata \\ ${ }^{3}$ Professor, Department of Obstetrics\& Gynaecology, PGIMS, Rohtak \\ ${ }^{4}$ Associate Professor, Department of Obstetrics\& Gynaecology, PGIMS, Rohtak \\ ${ }^{5}$ Senior Resident, Department of Orthopaedics, PGIMS, Rohtak \\ ${ }^{6}$ Senior Resident, Department of Obstetrics \& Gynaecology, Medical College, Kolkata \\ ${ }^{7}$ Senior Resident, Department of Obstetrics \& Gynaecology, DDU Hospital, Delhi \\ *Corresponding author E-mail:kriti.leo@gmail.com
}

\begin{abstract}
Background: Care of the critically ill pregnant women presents a unique challenge as the assessment, monitoring and the treatment must take into account both maternal and fetal wellbeing as well as physiological changes of pregnancy.

Objective: To assess the indications for critical care unit transfer of obstetric and postpartum cases and describe the profile and fetomaternal outcomes of such patients.

Methods: This prospective observational study was conducted in department of Obstetrics and Gynaecology of Medical College and Hospital, Kolkata from $1^{\text {st }}$ May 2013 to $30^{\text {th }}$ April 2014.Total 50 cases were included and data was analysed by frequency, percentage, paired and unpaired t test, chi square test and test of equality of proportions using SPSS version 20.

Results: $0.9 \%$ of total obstetric and postpartum admissions required critical care facilities and contributed to $16.67 \%$ of CCU admissions Mean age of patients included in our study was 25.4 years. Most of the patients were admitted antepartum ( $\mathrm{n}=37$, 74\%) with mean gestational age at admission being $34.2703 \pm 6.85018$ weeks. More patients presented with obstetric complications $(74 \%, \mathrm{n}=37)$ as compared to medical complications $(26 \%, \mathrm{n}=13)$. The most common indication for admission were major haemorrhage $(\mathrm{n}=18,36 \%)$ and hypertensive disorders of pregnancy $(\mathrm{n}=17,34 \%)$. There were 16(32\%) maternal deaths. MODS $(31.25 \%)$ and hypovolemic shock $(18.75 \%)$ were the most common causes of maternal death in our study.

Conclusion: The overall mortality was high, emphasizing the need for dedicated obstetric high dependency units.
\end{abstract}

Keywords: Care; Critical; Obstetric; Tertiary; Unit.

\section{Introduction}

Pregnancy and delivery can involve complications that require critical care facilities. A critically ill obstetric patient is a patient who develops acute but potentially reversible life-threatening complication during pregnancy or labour or puerperium for which she needs intensive monitoring, therapy and or life-support system. Critically ill obstetrical patients are usually young and initially healthy, so prognosis should hopefully be better on receiving timely intensive care facilities, as compared with other patients admitted to a critical care unit. This is strengthened by a study of 58 obstetric patients showing an observed mortality rate significantly lower than the expected mortality rate calculated by APACHE II score (Lewinsohn G et al.1994).Nevertheless, potential for life-threatening complications cannot be ignored, and despite therapeutic advances of last few decades, maternal mortality and morbidity continue to occur. Moreover, their management is complex due to the physiological changes of pregnancy and interventional dilemma due to concerns of fetal wellbeing, thereby emphasizing the need for multidisciplinary approach, which is, primarily, a close collaboration between the intensivist and the obstetrician. In developed countries, obstetrical patients account only for small proportion (0.1-0.9\%) of ICU admissions, where as this figure rises to $8.5 \%$ in developing countries (El Soh et al.1996 \& Karnad et al.2004).Usually, critically ill obstetric patients are cared for in the general intensive care unit (ICU); an obstetric ICU is only available in a small number of medical centres in developed countries. Only few studies have been published concerning ICU admissions of obstetric patients in developing world, hence the present study was conducted to evaluate the obstetric admissions to $\mathrm{CCU}$ in the settings of tertiary referral hospital with an attempt to identify the risk factors influencing maternal outcome, indications of admissions and feto-maternal outcomes.

\subsection{Aims \& objectives}

To assess the indications for critical care unit transfer of obstetric and postpartum cases and describe the profile and feto-maternal outcomes of such patients.

\section{Methods}

One-year prospective analysis of obstetric and postpartum admission was conducted in the Critical Care Unit attached to Medical 
College and Hospital, Kolkata, from $1^{\text {st }}$ May 2013 to $30^{\text {th }}$ April2014. Consent was signed through patient or attendant before including them in the study. Detailed clinical history and examination were taken and entered into a suitable proforma. The data retrieved for analysis contained age, parity, gestational age, booking status, area of residence, mode of delivery, indication for CCU admission, intervention in CCU, length of stay and outcome. These patients were followed until discharged from hospital or till death, whichever occurred first.

\subsection{Statistical analysis}

Data collected was analysed using mean, median, $\mathrm{p}$ values, frequency, percentages, paired and unpaired t test, test for equality of proportions using SPSS version 20.p value $<0.05$ taken as significant.

\section{Results}

A total of 110 obstetric patients were admitted to CCU during this period. We did analysis of 50 such cases. There were a total of 12,866 admissions for obstetric reasons in our hospital. These admissions included patients who were admitted at the hospital for antenatal complications, deliveries, abortion and its complications, ectopic pregnancy, obstetric haemorrhage and complications of the puerperium. $0.9 \%(n=110)$ of the total obstetric patients admitted at the hospital during the one-year period, required critical care services and obstetric cases represented $16.67 \%(n=110)$ of total admissions to the CCU. The mean age of critically ill patients in our study is 25.4 years.

As inferred from this Table 1, no demographic data was found to be a risk factor for maternal mortality ( $\mathrm{P}>0.05)$.

$42 \%$ were primigravida, $40 \%$ were primipara, $14 \%$ were second para, and $4 \%$ were multipara ,but primiparous group showed the maximum morality of $50 \%$ (10 out of 20 patients), next being the primigravid group with a mortality rate of $23.8 \%$ (5 out of $21)$ whereas females with two or more pregnancies showed a steep decline in mortality to as low as $14.3 \%$ (1 out of 7 ) to $0 \%$ ( 0 out of 2 patients)in those with three or more pregnancies. $62 \%(n=31)$ of patients requiring obstetric critical care were referrals from peripheral units to our tertiary care centre, with $22 \%(\mathrm{n}=11)$, $12 \%(n=6), 12 \%(n=6), 12 \%(n=6), 4 \%(n=2)$ of them being referred from subdivisional units or community health centre or state general hospital, primary health centres, district hospitals, private hospitals and private clinics respectively.

In our study antepartum admissions $(n=42,84 \%)$ were more as compared to postpartum admissions $(\mathrm{n}=8,16 \%)$.

Table 2 shows that $16 \%$ ( 8 out of 50 patients) underwent hysterectomy, $4 \%$ bilateral internal iliac artery ligation and $2 \%$ both of these procedures before transfer to CCU.LSCS was the most common operative intervention performed $(n=24,48 \%)$.

As is evident from Table 3, obstetric and nonobstetric complications accounted for $74 \%(n=37)$ and $26 \%(n=13)$ of admissions to critical care facilities, with major haemorrhage $(n=18,36 \%)$ and hypertensive disorder of pregnancy $(n=17,34 \%)$ being the most frequent causes.

$62 \%$ of patients required haemodynamic support, $54 \%$ required ventilatory support, $44 \%$ required inotropic support, $38 \%$ required high flow oxygen support, and $34 \%$ and $24 \%$ required antihypertensives and anticonvulsant therapy respectively. Dialysis was required in $2 \%$ of patients. $2 \%$ required evacuation of products of conception and hematoma respectively (Fig 1).

Table 1: Demographic Characteristics According to Maternal Outcome

\begin{tabular}{|c|c|c|c|c|c|}
\hline $\begin{array}{l}\text { CHARACTERISTIC FEATURE } \\
\text { NO OF PATIENTS }\end{array}$ & & $\begin{array}{l}\text { TOTAL } \\
50\end{array}$ & $\begin{array}{l}\text { SURVIVOR } \\
34\end{array}$ & $\begin{array}{l}\text { NON SURVIVOR } \\
16\end{array}$ & P VALUE \\
\hline \multirow{4}{*}{ age (years) } & $<=20$ & 10 & 6 & 4 & \multirow{4}{*}{0.324} \\
\hline & $21-25$ & 17 & 11 & 6 & \\
\hline & $26-30$ & 16 & 13 & 3 & \\
\hline & $>30$ & 7 & 4 & 3 & \\
\hline \multirow{2}{*}{ background } & Urban & 30 & 22 & 8 & \multirow{2}{*}{0.322} \\
\hline & Rural & 20 & 12 & 8 & \\
\hline \multirow[b]{2}{*}{ caste } & Hindu & 35 & 23 & 12 & \multirow{3}{*}{0.597} \\
\hline & Muslim & 15 & 11 & 4 & \\
\hline \multirow{4}{*}{ parity } & P0 & 21 & 16 & 5 & \\
\hline & P1 & 20 & 10 & 10 & \multirow{3}{*}{0.134} \\
\hline & P2 & 7 & 6 & 1 & \\
\hline & P3 or more & 2 & 2 & 0 & \\
\hline & $>=2$ visits & 35 & 26 & 9 & \\
\hline prenatal care & $<=1$ visit & 15 & 8 & 7 & 0.5 \\
\hline \multirow{2}{*}{ registration status } & Registered & 19 & 14 & 5 & \multirow{2}{*}{0.146} \\
\hline & Referred & 31 & 20 & 11 & \\
\hline
\end{tabular}

Table 2: Interventions Done Before CCU Transfer

\begin{tabular}{ll}
\hline TYPE OF INTERVENTION & NO OF CASES \\
\hline 1.Hysterectomy & 8 \\
2.BIIAL & 2 \\
3.BIIAL+Hysterectomy & 1 \\
4.Hysterotomy & 1 \\
5.MRP & 1 \\
6.Laparotomy & 4 \\
7.Balloon Tamponade Following D\&E & 1 \\
8.Only VD & 6 \\
9.Only LSCS & 24 \\
10.Died without operative intervention & 2 \\
TOTAL & 50 \\
\hline
\end{tabular}

BIIAL=bilateral internal iiac artery ligation, $\mathrm{MRP}=$ manual removal of placenta, $\mathrm{D} \& \mathrm{E}=$ dilatation and evacuation, $\mathrm{VD}=\mathrm{vaginal}$ delivery, LSCS=lower segment caesarean section 


\begin{tabular}{|c|c|c|c|c|c|}
\hline COMPLICATION & $\begin{array}{l}\text { PRIMARY DIAGNO- } \\
\text { SIS }\end{array}$ & TOTAL & SURVIVORS & NON SURVIVORS & MORTALITY\% \\
\hline \multirow{12}{*}{ OBSTETRIC $(n=37)$} & Major haemorrhage & 18 & 12 & 6 & $33.33 \%$ \\
\hline & 1.APH & 2 & 0 & 2 & $100 \%$ \\
\hline & 2.PPH & 8 & 6 & 2 & $25 \%$ \\
\hline & 3.Ruptured ectopic & 3 & 2 & 1 & $33 \%$ \\
\hline & $\begin{array}{l}\text { 4.Haemoperitoneum } \\
\text { following LSCS }\end{array}$ & & & & \\
\hline & $\begin{array}{l}\text { a.Broad ligament hema- } \\
\text { toma }\end{array}$ & 2 & 2 & 0 & $0 \%$ \\
\hline & $\begin{array}{l}\text { b.Rectus sheath hema- } \\
\text { toma }\end{array}$ & 1 & 1 & 0 & $0 \%$ \\
\hline & 5.Post D\&E & 2 & 1 & 1 & $50 \%$ \\
\hline & $\begin{array}{l}\text { HDP(hypertensive } \\
\text { disorder of pregnancy) }\end{array}$ & 17 & 12 & 5 & $29.40 \%$ \\
\hline & 1.Pre-eclampsia & 6 & 5 & 1 & $17 \%$ \\
\hline & Sepsis & 1 & 1 & 0 & $0 \%$ \\
\hline & $\begin{array}{l}\text { Gestational Tropho- } \\
\text { blastic Neoplasia }\end{array}$ & 1 & 1 & 0 & $0 \%$ \\
\hline \multirow{4}{*}{$\begin{array}{l}\text { NON-OBSTETRIC } \\
(n=13)\end{array}$} & $\begin{array}{l}\text { Anaesthesia complica- } \\
\text { tion }\end{array}$ & 1 & 1 & 0 & $0 \%$ \\
\hline & Liver disorders & 3 & 1 & 2 & $66.67 \%$ \\
\hline & Respiratory failure & 2 & 1 & 1 & $50 \%$ \\
\hline & Cardiac disease & 7 & 5 & 2 & $28.50 \%$ \\
\hline
\end{tabular}

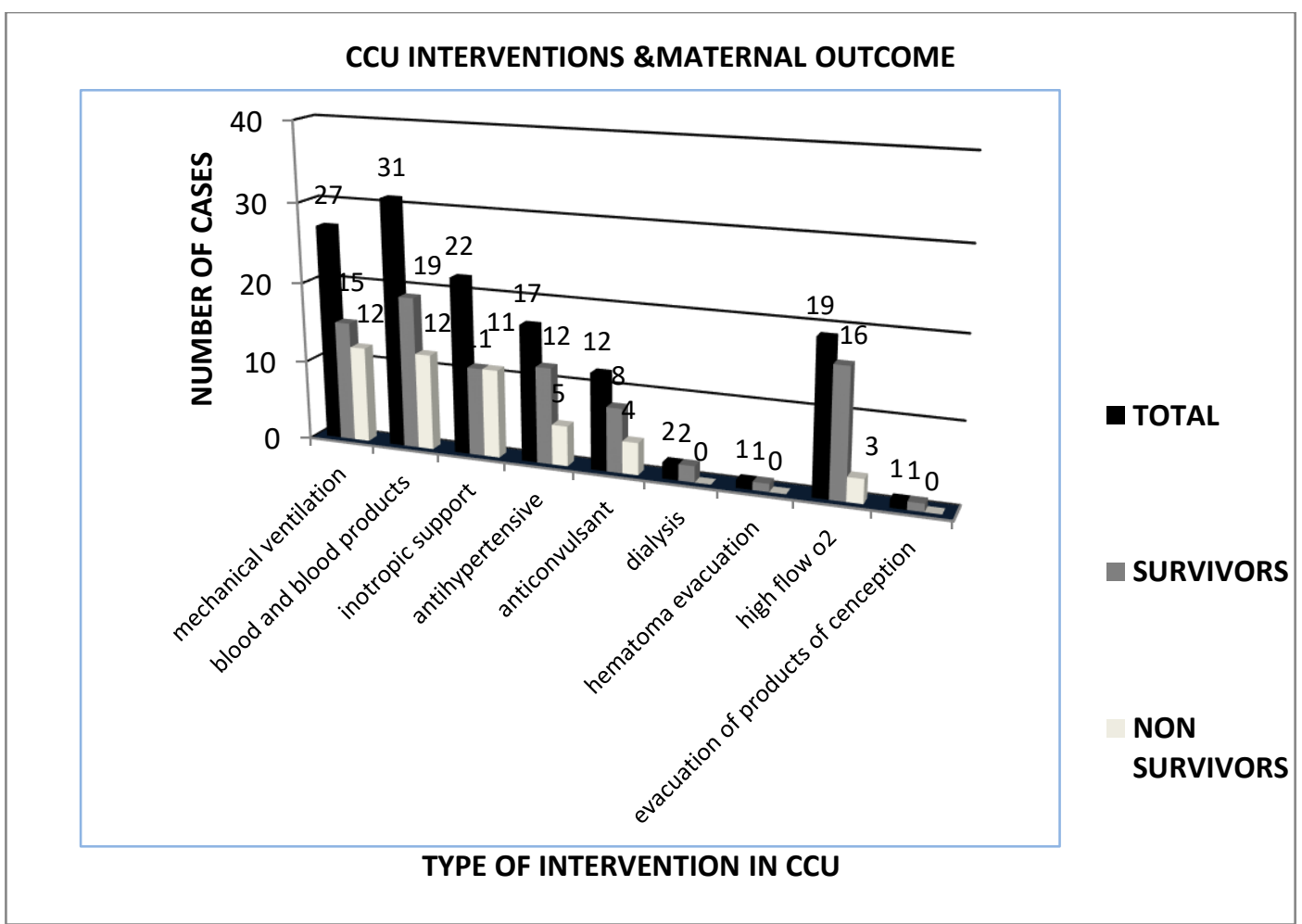

Fig. 1: Interventions Done in CCU and Maternal Outcome of These Interventions

Table 4: Blood Product Requirement

\begin{tabular}{lll}
\hline TYPE OF PRODUCT & NO. & PERCENTAGE \\
\hline No transfusion & 19 & $38 \%$ \\
$1-2 \mathrm{prbc} / \mathrm{wb}$ & 14 & $28 \%$ \\
$3-6 \mathrm{prbc} / \mathrm{wb}$ & 11 & $22 \%$ \\
$>6 \mathrm{prbc} / \mathrm{wb}$ & 4 & $8 \%$ \\
FFP & 19 & $38 \%$ \\
Platelet & 1 & $2 \%$ \\
\hline
\end{tabular}

Out of the 31 patients who received haemodynamic support, $28 \%$ of them required 1-2 prbc or whole blood and only $8 \%$ required more than 6 prbc or whole blood. $38 \%$ required FFP whereas only $2 \%$ required platelet transfusion (Table 4 ).

Table 5: Length of CCU Stay \& Maternal Outcome

\begin{tabular}{lllll}
\hline LOS(lengt & TO- & SURVI- & NON SUR- & MORTALI- \\
$\mathrm{h}$ of stay) & TAL & VORS & VIVORS & TY\% \\
\hline
\end{tabular}




\begin{tabular}{lllll}
\hline 1-3days & 30 & 21 & 9 & $30 \%$ \\
4-7days & 18 & 12 & 6 & $33 \%$ \\
$>7$ days & 2 & 1 & 1 & $50 \%$ \\
Total & 50 & 34 & 16 & \\
\hline
\end{tabular}

$60 \%$ of patients stayed in the CCU for $1-3$ days where as only $4 \%$ stayed for more than 7 days, with mortality being highest in the latter group (50\%) (Table5).

Out of 45 patients, 30 had live births, 10 had intrauterine fetal death and remaining five had undergone spontaneous abortion or medical termination of pregnancy (MTP). In our study $68 \%$ of patients who required critical care facilities improved where as $32 \%$ succumbed to death (Fig 2).

Multi organ dysfunction syndrome $(31.25 \%)$ and hypovolemic shock $(18.75 \%)$ were the most common causes of maternal death in our study (Fig 3).

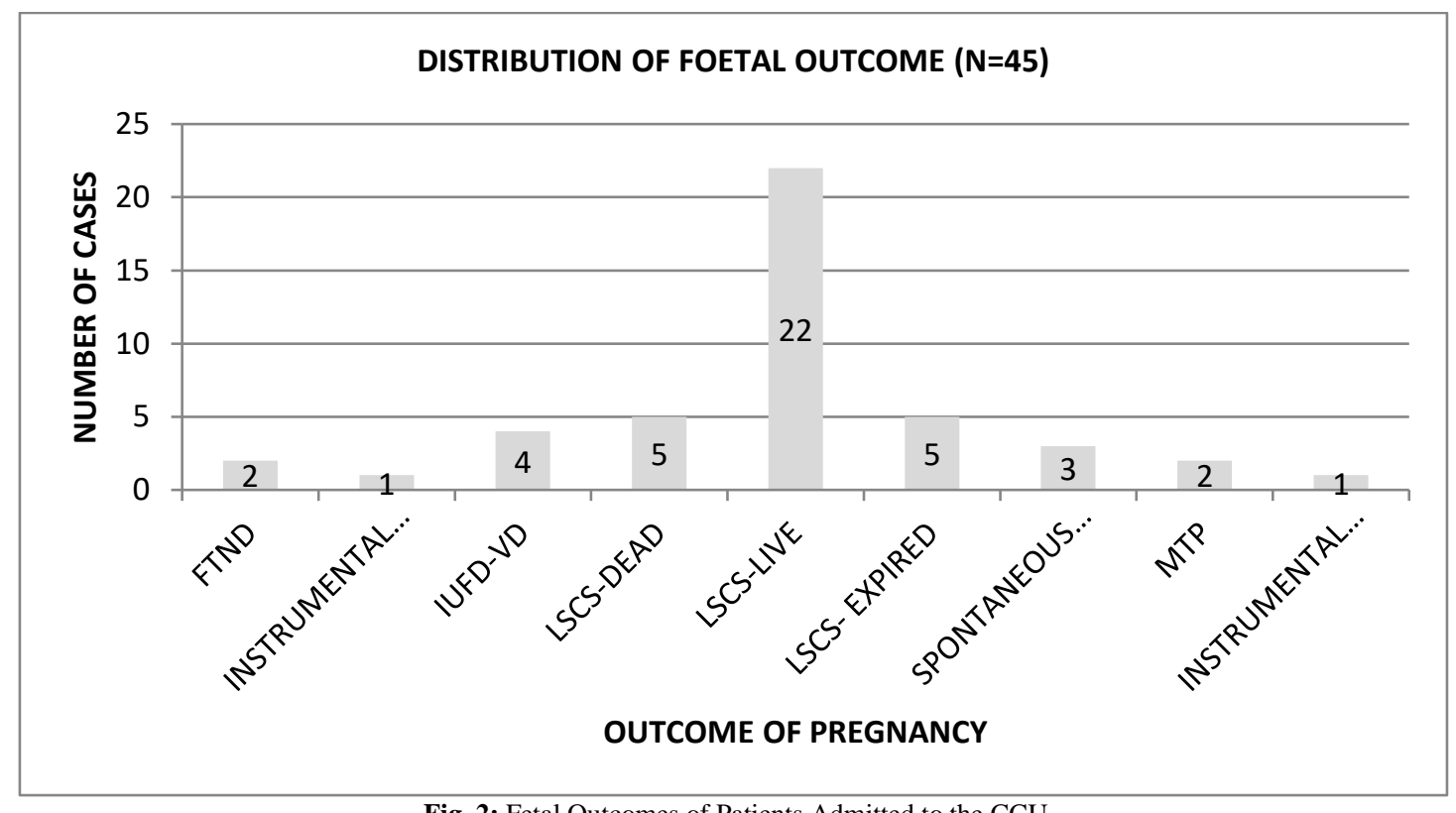

Fig. 2: Fetal Outcomes of Patients Admitted to the CCU

FTND=full tern normal delivery, $\mathrm{VD}=$ =vaginal delivery, $\mathrm{MTP}=$ medical termination of pregnancy

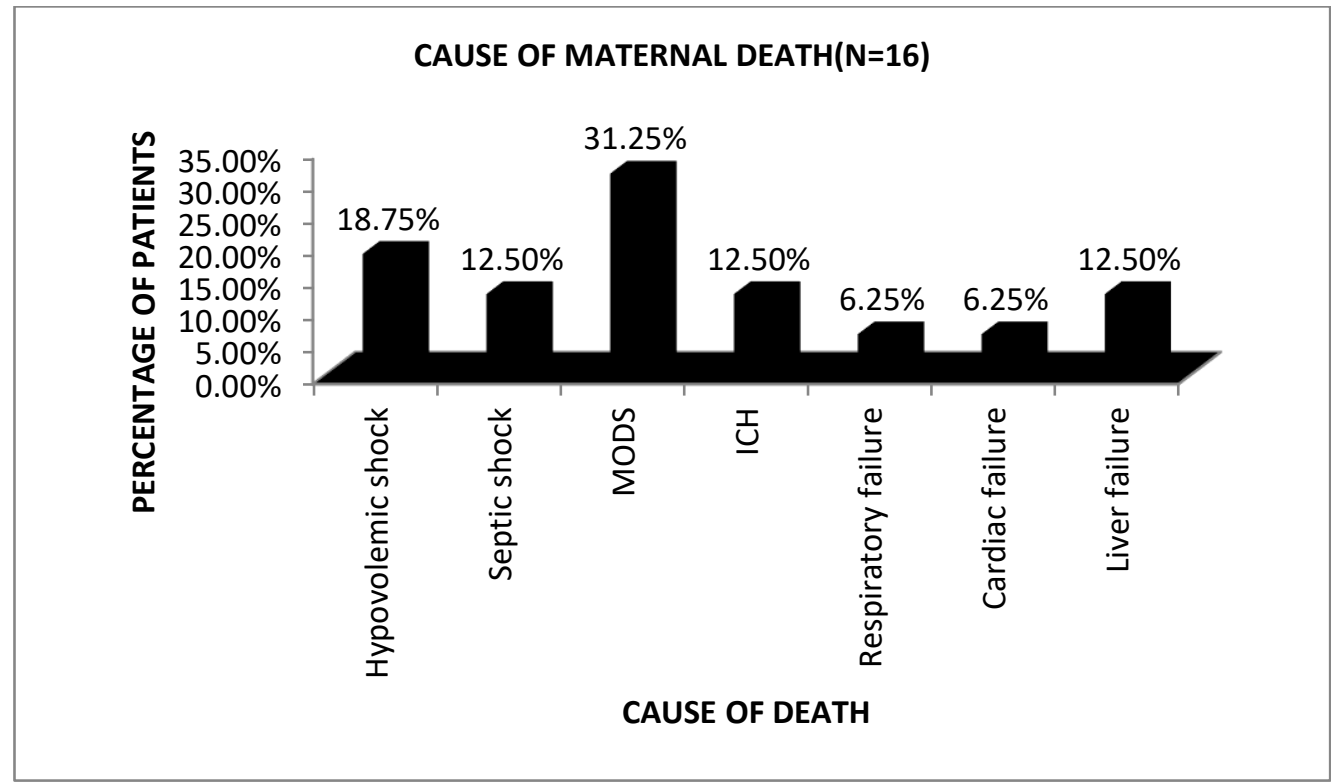

Fig. 3: Cause of Maternal Death

MODS=Multi organ dysfunction syndrome, ICH=intracranial haemorrhage. 


\section{Discussion}

In our study, we found that $0.9 \%(n=110)$ of the total obstetric patients admitted to the hospital during the one-year period, required critical care services, which is comparable to a study done India (Wakankar et al. 2015).Obstetric cases represented 16.67\% $(\mathrm{n}=110)$ of total admissions to our CCU, which is comparable to $14.7 \%$ of a Nigerian study (Ebrim LN et al.2012). Obstetric Admission rates to ICU were $0.75 \%$ in a study done by in Saudi Arabia (Aldawood, 2011). These variations might be due to differences in defining major morbidity criteria for CCU admission and availability of an alternative facility for intermediate care. The relatively high admission rate in our study might be due to the lack of a HDU, and hence patients not suitable for ward observation were transferred to the CCU. Mean age of patients in our study was 25.4 years which is comparable to another Indian study (Ghike S et al. 2012).62\%( 31 out of 50 patients) requiring obstetric critical care were referrals from peripheral units to our tertiary care centre which is similar to $61.8 \%$ of another study(Bhadade et al.2012).There was no significant association of any of the above demographic factors with mortality, similar to results obtained by Gupta Set al.2011.However, Munnur U et al.2005 showed that factors that were significantly associated with higher mortality rate were maternal age, absence of prenatal care, transfer to ICU > 24 hrs after onset of the acute problem, and severity of illness at the time of admission as assessed by the APACHE II score whereas number of previous pregnancies, parturient status (antepartum or postpartum) at the time of admission to ICU, gestational age, and emergency obstetric surgery did not influence outcome.

In our study, maximum number of obstetric admissions occurred during the antepartum period, with maximum admissions in the $3^{\text {rd }}$ trimester $(n=33,66 \%)$, followed by the postpartum period $(n=8$, $16 \%)$.Only $8 \% \quad(n=4)$ admissions were in the $1^{\text {st }}$ or $2^{\text {nd }}$ trimester.Similar results were obtained through a study done at CMC, Ludhiana (Yuvel et al.2008).Mean gestational age at the time of admission to hospital of antepartum patients was $34.2+6$ weeks. These aspects of gestational age highlight the maximum occurrence of complications in the third trimester and postpartum period and thus the importance of close supervision of patients during these periods.

In our study, $16 \% \%$ (8 out of 50 patients) underwent hysterectomy, $4 \%$ bilateral internal iliac artery ligation and $2 \%$ both procedures before transfer to $\mathrm{CCU}$.

Four of these were caesarean hysterectomies for intractable uterine haemorrhage due to atony; one was due to a ruptured interstitial ectopic pregnancy, one following broad ligament hematoma during LSCS, one due to torrential haemorrhage following D and E, and last one due to uterine perforation in choriocarcinoma.

As is evident from table $6 \%$ (3 out of 50 patients) underwent bilateral internal iliac artery ligation, indications being severe PPH along with hysterectomy, intractable haemorrhage from genital tract trauma following vaginal delivery and broad ligament hematoma following LSCS. In our study indications for laparotomy were uterine perforation following $\mathrm{D}$ and $\mathrm{E}$, reoperation for haemostasis in rectus sheath hematoma following LSCS, and salpingectomy $(n=2)$ in remaining cases for ruptured tubal pregnancies. Manual removal of placenta was done under general anaesthesia for retained placenta following vaginal delivery of stillborn baby in one of the patients. One week later due to persistent bleeding per vaginum and ultrasound suggestive of retained products, this patient underwent dilatation and evacuation of retained products of conception. Only one patient with a previous uterine scar, required balloon tamponade, following dilatation and evacuation due to excessive haemorrhage during the procedure, but later she succumbed to death probably due to delayed diagnosis of caesarean scar pregnancy.

The hysterotomy was performed at 24-week period of gestation, indication being chronic hypertension superimposed on severe pre eclampsia with signs of impending eclampsia in a patient with previous two LSCS.

The undelivered patients died with fetus in utero. Fetuses were delivered by hysterotomy and post mortem caesarean section respectively. The post mortem hysterotomy was performed at 16 weeks of gestation in a 35-year-old G3P1L1A1 with anaemia and Hepatitis B associated with decompensated liver failure whereas post mortem caesarean section was performed at 35 weeks of gestation in a primigravida with twin pregnancy with history of treatment for primary infertility who presented to us with cardiac failure and succumbed to death eventually. When cardiac arrest occurs during late pregnancy, cardio-pulmonary resuscitation (CPR) is difficult. The airway should be secured without delay, and the patient should be positioned to ensure left lateral displacement of the uterus. Unfortunately, this results in fewer effective CPR. A decision regarding Caesarean delivery should be made immediately. Current data suggest that this should be performed within 5 minutes, to ensure viability of the foetus (Zdolsek HJ et al. 2009).

Obstetric and nonobstetric patients contributed to $74 \%(\mathrm{n}=37)$ and $26 \%(n=13)$ of total admissions to CCU. This is similar to study done by Bhatt et al.2013.The leading reason for admission in the obstetric group was major haemorrhage $(n=18,36 \%)$ in antepartum, postpartum, post abortal, post ectopic and post caesarean section patients, with 8 out of 18 cases being due to postpartum haemorrhage. Major causes of PPH were related to uterine atony (6), retained placenta following vaginal stillbirth (1), perineal trauma (1).Uterine Uterine atony was noted in 4 cases and 2 cases following LSCS and Vaginal Delivery respectively. All 4 cases of PPH following LSCS were seen in post caesarean pregnancies with one having scar rupture and another having placenta acreta. Out of 2 cases of PPH following vaginal delivery, two were following stillbirths. It is well known that IUFD is a risk factor for $\mathrm{PPH}$

HDP formed the second largest group in this category as $34 \%$ $(n=17)$ required critical care and 11 of these admissions were due to eclampsia. Although it was the second most common reason for admissions of the obstetric patients to the $\mathrm{CCU}$, maternal mortality rate from this complication $(36 \%)$ was higher than that due to obstetric haemorrhage $(33.33 \%)$. The higher maternal morbidity and mortality due to eclampsia in developing countries have been ascribed to late referral, delay in hospitalization, late transportation, unbooked status of patients and multiple seizures prior to admission. This is similar to study conducted in Nigeria (Ebrim $\mathrm{LN}$ et al .2012). Main non obstetric indication for CCU admission was cardiovascular disorder $(n=7)$ followed by hepatic disorders $(n=3)$, respiratory disorders $(n=2)$, anaesthetic complication $(n=1)$. Cardiovascular problems included valvular heart disease $(n=5)$, acute heart failure $(\mathrm{n}=1)$ and peripartum cardiomyopathy $(\mathrm{n}=1)$ similar to results obtained by Bhatt et al .2013. Among indirect causes, cardiac and liver failure was most common causes of death, accounting for $25 \%$ of all deaths. None of the diagnoses were found to be a significant risk factor for maternal mortality $(\mathrm{P}>0.05)$. Some of the associated medical conditions included nutritional anaemia $(n=10,20 \%$,$) , mitral valve disease (n=5,10 \%)$ ,hypothyroid

$(\mathrm{n}=4,8 \%)$, asthma $(\mathrm{n}=3,6 \%)$, tuberculosis $(\mathrm{n}=1,2 \%), \operatorname{SLE}(\mathrm{n}=1,2 \%), \mathrm{ch}$ ronic hypertension $(\mathrm{n}=1,2 \%)$ similar to results obtained by Gupta $\mathrm{S}$ et al.2011. 
Among CCU interventions, mechanical ventilation, transfusion of blood and blood products, ionotropes, high-flow oxygen, antihypertensive , anticonvulsants, dialysis, evacuation of hematoma and retained products of conception was required in $54 \%(\mathrm{n}=27)$, $62 \%(\mathrm{n}=31), 44 \%(\mathrm{n}=22), 38 \%(\mathrm{n}=19 \%), 34 \%(\mathrm{n}=17), 24 \%(\mathrm{n}=12), 4 \%($ $\mathrm{n}=2), 2 \%(\mathrm{n}=1), 2 \%(\mathrm{n}=1)$ respectively similar to of Bhatt et al.2013 and Gupta Set al. 2011. Leung et al.2010and Lapinsky et al.1997 in their studies showed that mechanical ventilation was required in $12-55 \%$ of the obstetric patients admitted to an ICU. However, during the course of treatment, none of these interventions was not found to be a significant risk factor for mortality $(\mathrm{P}>0.05)$ similar to results of Gupta S et al.2011.

We found that as the duration of ventilation increased, the rate of mortality increased being $26.31 \%$ (5 out of 19)mortality in those who were on ventilator for 1-3days to $80 \%(4$ out of 5) in those for 4-6days to $100 \%$ (o out of 3 )in that requiring mechanical ventilation for 7 or more days with significant difference in mortality for that requiring ventilation for more than seven days $(p<0.001)$. This This may be due to increased ventilator associated infections with increasing duration of mechanical support. Only one tracheostomy was performed in a patient who was on ventilator for 10 days. She had been preexisting SLE and eventually succumbed to death. Bhat et al. 2013 and Bhadade et al.2012 in their respective studies also reported one tracheostomy amongst 65 and 122 patients respectively.

Blood products given included packed cells or whole blood (mean3.30 units), and fresh frozen plasma (mean 3.05 units). A study in Hong Kong reported that $54 \%$ of their patients required blood transfusion (Vivian et al.2014). In view of the high mortality associated with anaemia, as studied by Munnur et al.2005 and Karnad et al.2004, prevention and prompt treatment of the same would help in cutting short the stay and mortality of patients in the critical care unit. In addition to blood, $38 \%(n=19)$ required transfusion of FFP. Bhadade et al.2012 reported that $54 \%$ of patients required FFP. This difference might be due to the fact that in their study $37 \%$ were admitted with Hepatits as compared to only $6 \%$ with Hepatitis in our study. Thus, immediate and ample availability of blood and blood components in a critical care unit help in reducing the mortality of obstetrical emergencies. Out of the 31 patients who received blood and blood product transfusion, 2 developed transfusion related acute lung injury (TRALI).The abovementioned patients received 2 units of whole blood each and 3 and 2 units of packed red blood cells respectively. One of them had been pre-existing dengue fever.

We found that $60 \%(n=30)$ stayed for less than 4 days in the CCU whereas only $4 \%(n=2)$ stayed for more than 7 days, with mean length of stay being 3.4 days similar to Gupta $\mathrm{S}$ et al.2011 ${ }^{9}$ Also, mortality rate was $31.25 \%$ in patients staying for less than or equal to 7 days of admission as compared to $50 \%$ for those staying more than a week in the CCU. In our study, the mean duration of stay in the CCU for survivors was 3.35 days whereas for non survivors it was 3.6 days, which was not significantly different. Gupta $S$ et al.2011 found that the mean duration of stay in the ICU was significantly longer in survivors as compared to non-survivor, however, mean length of survival in both studies are comparable.

In our study, out of 45 patients, 30 had live births, 10 had IUFD and remaining five had undergone spontaneous abortion or medical termination of pregnancy. Out of 30 live births, 5 expired within three days of delivery. $25.6 \%$ of live births were low birth weight $(<2.5 \mathrm{~kg})$.Mean birth-weight was $2.56 \mathrm{~kg}$.

In our study, mortality was $32 \%(n=16)$ with $31.25 \%(n=5)$ and $68.75 \%(n=11)$ of them being registered and referred cases respectively similar to results obtained by Bhat PB et al. 2013. There was no significant difference in mortality between these two groups. Lapinsky et al.1994 reported mortality rates of critically ill obstetric patients admitted to the $\mathrm{CCU}$ in the range from 0 to $6 \%$ whereas mortality rates in Indian series were $30-34 \%$ (Bhadade et al. 2011 \& Bhatt et al.2013) which coincides with mortality rate of our study. Our hospital being a tertiary referral centre, majority of the patients are referred in advanced stage of disease, which might explain the higher mortality seen in our patients. The majority of our patients were admitted postoperatively, which could have adversely affected the outcome in some cases. Pre-eclamptic or eclamptic patients might benefit from preoperative admission to the CCU for medical conditions optimization before anaesthesia and surgery, instead of nursing them in the wards. There is also the need for co-operation between the obstetrician and anaesthetist in the management of these high-risk patients. The availability of prenatal care may be an important factor in successful outcome in critically ill obstetric patients.

Multi-organ dysfunction syndrome (MODS) ( $n=5,31.2 \%)$ was found to be the most common cause of maternal mortality, while other causes were hypovolemic shock $(n=3,18.75 \%)$ and septic shock syndrome ,liver failure and intra cranial haemorrhage $(\mathrm{ICH})(\mathrm{n}=2,12.5 \%)$ similar to results obtained by a study in Pakistan (Shaikh et al.2013). Optimum care of circulation, respiration at an early stage can clearly minimize the incidence of multiorgan failure and late mortality in all critically ill obstetric patients. The ICH can be prevented by controlling the hypertension.

\section{Conclusion}

Our study highlights the large number of obstetric patients who require intensive care in developing country like India and also the relatively high maternal mortality rate. This may be because of the large number of deliveries taking place annually and also the poor availability and lack of prenatal check-ups .Moreover dedicated obstetric high dependency units in tertiary hospitals can ensure there is no delay in patient management and intensive care can be instituted at the earliest.

Our study had several limitations: it was conducted in a single centre. The sample size was small, APACHE score for severity of illness was not calculated, and ICU mortality rate should be interpreted only after taking into account the severity of illness. There is ample scope for further elaborate study in this field and larger endeavours with large sample size will probably reveal more important facts regarding obstetric critical care.

\section{References}

[1] Lewinsohn G, Herman A, Leonov Y, Klinowski E (1994) critically ill obstetrical patients: outcome and predictability. Critical Care Medicine; 22:1412-4. $\quad$ https://doi.org/10.1097/00003246199409000-00010.

[2] Karnad DR, Lapsia V, Krishnan A, Salvi VS(2004)Prognostic factors in obstetric patients admitted to an Indian intensive care unit. Critical Care Medicine; 32(6): 1294-9. https://doi.org/10.1097/01.CCM.0000128549.72276.00.

[3] El-Solh AA, Gran BJ (1996) A comparison of severity of illness scoring systems for critically ill obstetric patients. Chest; 110(5): 1299-304. https://doi.org/10.1378/chest.110.5.1299.

[4] Wakankar R, Patankar A, Humne A, Khadse A (2015) Study of Obstetric Cases Admitted in ICU. SAS Journal of Surgery; 1 (11):11-17

[5] Ebirim LN, OjumS (2012) Admissions of obstetric patients in the intensive care Unit: A 5year review. Journal of Medicine and Medical Sciences; 3(11):741- 4 .

[6] Aldawood A (2011) Clinical characteristics and outcomes of critically ill obstetric patients: a ten-year review. Annals of Saudi Medicine; 31:518-22. https://doi.org/10.4103/0256-4947.84631.

[7] Ghike S, Asegaonkar P(2012)Why obstetric patients are admitted to intensive care unit? A retrospective study. Journal of South Asian Federation of Obstetrics and Gynaecology; 4(2): 90-2. https://doi.org/10.5005/jp-journals-10006-1181. 
[8] Bhadade R, De Souza R, More A, Harde M(2012)Maternal outcomes in critically ill obstetrics patients: A unique challenge. Indian Journal of Critical Care Medicine; 16(1):8-16. https://doi.org/10.4103/0972-5229.94416.

[9] Gupta S, Naithani U, Doshi V, Bhargava V, Bhavani VS (2011)Obstetric critical care: a prospective analysis of clinical characteristics, predictability, and fetomaternal outcome in a new dedicated obstetric intensive care unit. Indian Journal of Anaesthesia; 55(2):146-53. https://doi.org/10.4103/0019-5049.79895.

[10] Munnur U, Karnad DR, Bandi VD, Lapsia V, Suresh MS, Ramshesh $\mathrm{P}$, et al(2005) Critically ill obstetric patients in an American and an Indian public hospital: Comparison of case-mix, organ dysfunction, intensive care requirements, and outcomes.Intensive Care Med; 31:1087-94. https://doi.org/10.1007/s00134-005-2710-5.

[11] Yuvel VI, Kaur V, Kaur G, Andappan A, Afzal L(2008) Critical care in obstetrics - scenario in a developing country. Journal of Obstetrics and Gynecology India; 58(3):217-20

[12] Zdolsek HJ, Holmgren S, Wedenberg $\mathrm{K}$, Lennmarken $\mathrm{C}(2009)$ Circulatory arrest in late pregnancy: caesarean section a vital decision for both mother and child. Acta Anaesthesiology Scandinavia; 53:828-9. https://doi.org/10.1111/j.13996576.2009.01970.x.

[13] Bhat PB, Navada MH, Rao SV, Nagarathna G(2013)Evaluation of obstetric admissions to intensive care unit of a tertiary referral center in coastal India. Indian Journal of Critical Care Medicine; 17: 34-7. https://doi.org/10.4103/0972-5229.112156.

[14] Leung NY, Lau AC, Chan KK, Yan WW (2010) Clinical characteristics and outcomes of obstetric patients admitted to the intensive care unit: A 10-years retrospective review. Hong Kong Medical Journal; 16:18-25.

[15] Lapinsky SE, Kruczynski K, Seaward GR, et al (1997) Critical care management of the obstetric patient. Canadian Journal of Anaesthesia; 44:325-9. https://doi.org/10.1007/BF03015374.

[16] Vivian KS, Lo TK, Tsang HH, Lau WL, Leung WC (2014) Intensive care unit admission of obstetric cases: a single centre experience with contemporary update. Hong Kong Medical Journal; 20:24-31

[17] Shaik S, Bano N, Abassi R, Balouch R(2013)Obstetric admission to the ICU: A one year review. Medical Channel; 19:59-63. 